\title{
Crab claw pattern on corneal topography: pellucid marginal degeneration or inferior keratoconus?
}

M Koc, K Tekin, M Inanc, P Kosekahya

and $\mathrm{P}$ Yilmazbas

\begin{abstract}
Purpose To evaluate the topographic, tomographic, and densitometric properties of patients with pellucid marginal degeneration (PMD) and inferior keratoconus.

Patients and methods Retrospective, comparative case series. Forty-seven eyes of 32 patients with crab claw patterns were identified from 2751 patients with corneal ectasia. They were divided into two groups, inferior keratoconus and PMD, based on clinical findings.

The topographic, tomographic, and densitometric measurements were analyzed. Results PMD was detected in 11 eyes of eight patients (mean age $50.2 \pm 11.1$ years), and inferior keratoconus was detected in 36 eyes of 24 patients (mean age $34.7 \pm 10.1$ years). The control group consisted of 40 patients (33.1 \pm 4.6 years). The thinnest corneal point and maximum anterior and posterior elevation points were located lower in the PMD than in the inferior keratoconus $(P<0.01)$. In the PMD, all deviation indices were higher than the controls $(P<0.01)$, whereas the deviation indices, except $D t$ $(P=0.960)$, were lower than the inferior keratoconus $(P<0.01)$. The densitometry values of PMD were significantly higher than those of the controls in all zones and layers $(P<0.01)$ and significantly higher than the densitometry values of inferior keratoconus in the $6-10$ and $10-12 \mathrm{~mm}$ zones $(P<0.05)$. Conclusion There is a higher probability of a patient with crab claw pattern on the topography of having inferior keratoconus than having PMD. Therefore, analyzing only the anterior corneal surface is not sufficient in differential diagnosis. Tomographic and densitometric evaluations may facilitate the differential diagnosis.

Eye (2018) 32, 11-18; doi:10.1038/eye.2017.198; published online 22 September 2017
\end{abstract}

\section{Introduction}

Keratoconus and pellucid marginal degeneration (PMD) are bilateral, progressive, ectatic corneal disorders characterized by thinning of the cornea. In PMD, the thinning extends $1-2 \mathrm{~mm}$ away from the inferior limbus, and the corneal protrusion occurs above the area of thinning. ${ }^{1}$ Crab claw or butterfly patterns on the sagittal topographic map of anterior corneal curvature reveal steepening of the inferior corneal periphery and flattening of the cornea along the vertical meridian. ${ }^{2}$ In keratoconus, corneal thinning usually occurs in the paracentral region, and corneal topography shows central or inferior steepening and asymmetric bowtie patterns. ${ }^{3}$ Inferior keratoconus, in which the cone is localized away from the corneal center and a crab claw pattern is seen on the sagittal topographic map, is often confused with PMD. ${ }^{4,5}$ However, both prognosis and management of PMD and keratoconus are different, and PMD should be distinguished from keratoconus. ${ }^{6}$

A significant number of PMD cases reported in the literature actually have corneal topographies compatible with inferior keratoconus. These eyes do not show the classic band-like inferior thinning that is best demonstrated by a full-coverage $(12 \mathrm{~mm})$ corneal thickness map. In inferior keratoconus, the sagittal curvature map does not display the true corneal shape, and it exaggerates the presumed location of the cone., 5 Therefore, analyzing only the anterior corneal surface without additional information is not sufficient in the differential diagnosis of inferior keratoconus and PMD.

The assessment of corneal densitometry in patients with different corneal pathologies has recently attracted increasing attention. 8,9 Densitometric evaluation provides quantitative
Department of Ophthalmology, Ulucanlar Eye Training and Research Hospital, Ankara, Turkey

\section{Correspondence:}

M Koc, Department of Ophthalmology, Ulucanlar Eye Training and Research Hospital, 06340 AltindagAnkara, Turkey Tel: +90 312 5428464697; Fax: +90 3123123805 E-mail: drmukoc@ hotmail.com

Received: 19 December 2016

Accepted in revised form:

1 August 2017

Published online:

22 September 2017 
data of the transparency of the cornea at different depths and in different zones. For corneal transparency, collagen fibrils should be arranged orthogonally and regularly with a small diameter, and keratocyte distribution must be compatible with it. ${ }^{10}$ In ectatic diseases, serious structural changes occur in the corneal stroma, and both the structure and the sequence of collagen fibrils are disrupted. ${ }^{11,12}$ Therefore, the corneal densitometric values increase. ${ }^{12}$ When planning this study, we thought that, even though PMD and inferior keratoconus appear similar on sagittal curvature maps, there may be regional densitometric differences because different regions of the cornea are affected and this difference can be used to differentiate the two diseases.

In previous studies, the topographic, tomographic, and aberrometric features of PMD and keratoconus have been assessed several times. ${ }^{4,5,13-16}$ However, the number of studies evaluating inferior keratoconus and PMD is limited. ${ }^{4,14}$ The aim of our study was to evaluate the topographic, tomographic, and densitometric properties of patients with PMD and inferior keratoconus to facilitate the differential diagnosis of these two diseases.

\section{Materials and methods}

This retrospective, cross-sectional study was conducted according to the tenets of the Declaration of Helsinki. Ethics committee approval was obtained from the Ankara Numune Training and Research Hospital. For this study, we examined the medical records of patients who were seen for corneal ectasia at the Ankara Ulucanlar Eye Training and Research Hospital from October 2013 to October 2016. Inclusion criteria consisted of having a classic crab claw pattern on the sagittal curvature map, detected using the Pentacam HR (Oculus Optikgeräte $\mathrm{GmbH}$, Wetzlar, Germany), with flattening along a vertical or oblique axis at least one diopter and a crescentshaped steepening pattern in the inferior cornea that extended toward the line perpendicular to the axis of flattening. Patients with a crab claw pattern were classified into two groups, based on clinical findings, as inferior keratoconus and PMD. Other corneal ectasia patients with a crab claw pattern on their corneal topography and patients who did not have appropriate data were not included in the study. PMD diagnosis was based on the presence of a crab claw pattern in the sagittal curvature maps and ocular findings, including the typical band-like inferior corneal thinning and protrusion above the thinning, lack of the Fleischer ring, corneal infiltration, and vascularization. ${ }^{1,17}$ The diagnosis of inferior keratoconus was based on the presence of a crab claw pattern in the sagittal curvature maps and at least one biomicroscopic sign, such as a conical protrusion, Vogt's striae, and the Fleischer ring. Eyes with suspect PMD or suspect keratoconus were excluded from the study. The control group was randomly selected from a database of candidates for refractive surgery and contact lens users with mixed astigmatism. One eye of each control subject was randomly chosen. Patients with a history of anterior segment surgery, ocular surface problems, long-term topical eye drop usage, and serious corneal scarring were excluded. The measurements were performed after removing the rigid gas-permeable contact lenses for at least 3 weeks and soft contact lenses for at least 1 week.

All subjects underwent topographic, tomographic, and densitometric analyses via a rotating Scheimpflug camera after the clinical examination. A single expert examiner acquired Pentacam images. Image quality was checked, and only one examination with a high-quality factor was recorded for each eye. The following data were analyzed: (1) Flat $\mathrm{K}\left(\mathrm{K}_{1}\right)$ and steep $\mathrm{K}\left(\mathrm{K}_{2}\right)$ for the central $3.0 \mathrm{~mm}$ of the cornea, maximum $\mathrm{K}\left(K_{\max }\right)$, thinnest corneal thickness, the coordinates of maximum anterior and posterior elevation points in the $y$ axis (best-fit sphere (BFS) set to manual, float, sphere, diameter $=8.0 \mathrm{~mm}$ ), and corneal aspherity ( $Q$-value in central 30 degree) in the sagittal curvature map from the obtained $12 \mathrm{~mm}$ corneal area; (2) Df (deviation of normality of the front elevation), $\mathrm{Db}$ (deviation of normality of the back elevation), $\mathrm{Dp}$ (deviation of normality of pachymetric progression), Dt (deviation of normality of corneal thinnest point), Da (deviation of normality of relational thickness), final D (overall deviation of normality), average pachymetric progression index $\left(\mathrm{PPI}_{\mathrm{avg}}\right)$, and average Ambrósio relational thickness $\left(\mathrm{ART}_{\mathrm{avg}}\right)$ indices in the BelinAmbrósio Enhanced Ectasia Display III analysis; and (3) finally, the corneal densitometry measurement performed over a $12 \mathrm{~mm}$ diameter of the cornea.

Corneal densitometry was examined with the densitometry software of the Pentacam HR (Oculus Optikgeräte $\mathrm{GmbH}$, Wetzlar, Germany). It measures the backscattered light over a $12 \mathrm{~mm}$ diameter area. This area is further divided into four concentric zones. The first zone consists of a circular area $2 \mathrm{~mm}$ in diameter at the center of the cornea, and the second zone is the $2-6 \mathrm{~mm}$ annular area around it. The third zone is the $6-10 \mathrm{~mm}$ annular area, and the fourth zone is the $10-12 \mathrm{~mm}$ annular area. This analysis also provides densitometric values of the cornea at three different depths. The anterior layer consists of the superficial $120 \mu \mathrm{m}$, and the posterior layer consists of $60 \mu \mathrm{m}$ of the innermost cornea. The central corneal layer is between these two layers. The corneal densitometry values are expressed as the pixel luminance per unit volume in the Scheimpflug image, and they are expressed in grayscale units. The measurements range from 0 (maximum transparency) to 100 (completely opaque cornea) according to the degree of backscattering light from the cornea. ${ }^{8}$ 


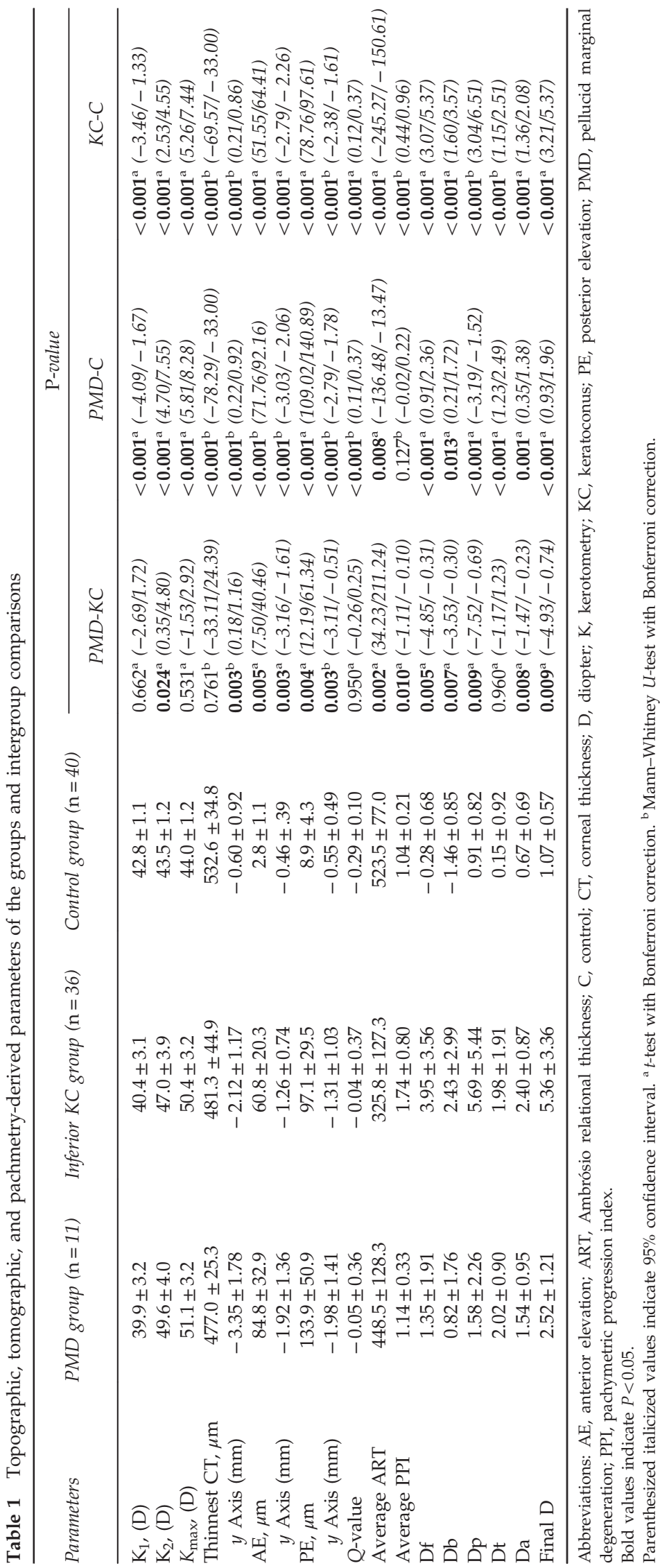


Table 2 Comparison of corneal densitometric measurements of the groups and intergroup comparisons

\begin{tabular}{|c|c|c|c|c|c|c|}
\hline \multirow[t]{2}{*}{ Region } & \multirow[t]{2}{*}{$P M D(\mathrm{n}=11)$} & \multirow{2}{*}{$\begin{array}{l}\text { Inferior keratoconus } \\
\qquad(\mathrm{n}=36)\end{array}$} & \multirow{2}{*}{$\begin{array}{l}\text { Control group } \\
\quad(\mathrm{n}=40)\end{array}$} & \multicolumn{3}{|c|}{ P-value } \\
\hline & & & & $P M D-K C$ & $P M D-C$ & $K C-C$ \\
\hline \multicolumn{7}{|c|}{ 0-2 mm zone } \\
\hline Anterior & $23.95 \pm 8.42$ & $23.90 \pm 5.40$ & $18.41 \pm 1.13$ & $0.981^{\mathrm{a}}(-4.24 / 4.35)$ & $<\mathbf{0 . 0 0 1}^{\mathrm{a}}(2.84 / 8.23)$ & $<\mathbf{0 . 0 0 1}^{\mathrm{a}}(3.74 / 7.22)$ \\
\hline Central & $14.49 \pm 2.95$ & $14.36 \pm 2.62$ & $11.91 \pm 0.50$ & $0.894^{\mathrm{a}}(-1.75 / 1.99)$ & $<\mathbf{0 . 0 0 1}^{\mathrm{a}}(1.61 / 3.54)$ & $<\mathbf{0 . 0 0 1}^{\mathrm{a}}(1.60 / 3.29)$ \\
\hline Posterior & $11.74 \pm 1.79$ & $11.26 \pm 1.49$ & $9.84 \pm 0.71$ & $0.382^{\mathrm{a}}(-0.61 / 1.56)$ & $<\mathbf{0 . 0 0 1}^{\mathrm{b}}(1.19 / 2.60)$ & $<\mathbf{0 . 0 0 1}^{\mathrm{b}}(0.89 / 1.95)$ \\
\hline Total & $16.71 \pm 4.15$ & $16.51 \pm 3.03$ & $13.38 \pm 0.70$ & $0.859^{\mathrm{a}}(-2.09 / 2.50)$ & $<\mathbf{0 . 0 0 1}^{\mathrm{a}}(1.97 / 4.68)$ & $<\mathbf{0 . 0 0 1}^{\mathrm{a}}(2.14 / 4.10)$ \\
\hline \multicolumn{7}{|c|}{$2-6 \mathrm{~mm}$ zone } \\
\hline Anterior & $20.88 \pm 5.73$ & $20.88 \pm 3.37$ & $16.45 \pm 1.46$ & $0.999^{\mathrm{a}}(-2.78 / 2.79)$ & $<\mathbf{0 . 0 0 1}^{\mathrm{b}}(2.44 / 4.41)$ & $<\mathbf{0 . 0 0 1}^{\mathrm{b}}(3.25 / 5.59)$ \\
\hline Central & $12.70 \pm 1.90$ & $12.84 \pm 1.72$ & $10.85 \pm 0.58$ & $0.907^{\mathrm{a}}(-1.29 / 1.15)$ & $<\mathbf{0 . 0 0 1}^{\mathrm{a}}(1.23 / 2.60)$ & $<\mathbf{0 . 0 0 1}^{\mathrm{a}}(1.41 / 2.56)$ \\
\hline Posterior & $11.15 \pm 1.54$ & $10.77 \pm 1.53$ & $9.31 \pm 0.71$ & $0.465^{\mathrm{b}}(-0.67 / 1.45)$ & $<\mathbf{0 . 0 0 1}^{\mathrm{b}}(1.19 / 2.49)$ & $<\mathbf{0 . 0 0 1}^{\mathrm{b}}(0.91 / 1.99)$ \\
\hline Total & $14.94 \pm 2.93$ & $14.83 \pm 2.06$ & $12.25 \pm 0.74$ & $0.887^{\mathrm{a}}(-1.47 / 1.69)$ & $<\mathbf{0 . 0 0 1}^{\mathrm{b}}(1.67 / 3.70)$ & $<\mathbf{0 . 0 0 1}^{\mathrm{b}}(1.88 / 3.27)$ \\
\hline \multicolumn{7}{|c|}{ 6-10 mm zone } \\
\hline Anterior & $24.03 \pm 7.16$ & $18.26 \pm 3.56$ & $16.37 \pm 2.49$ & $\mathbf{0 . 0 0 1}^{\mathrm{b}}(2.58 / 8.98)$ & $<\mathbf{0 . 0 0 1}^{\mathrm{b}}(5.11 / 9.47)$ & 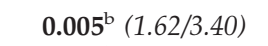 \\
\hline Central & $16.39 \pm 4.27$ & $12.18 \pm 2.17$ & $11.22 \pm 1.23$ & $<\mathbf{0 . 0 0 1}^{\mathrm{a}}(2.27 / 6.13)$ & $<\mathbf{0 . 0 0 1}^{\mathrm{b}}(3.63 / 6.82)$ & $0.077^{\mathrm{b}}(-0.18 / 1.66)$ \\
\hline Posterior & $14.25 \pm 3.69$ & $11.03 \pm 1.89$ & $10.29 \pm 1.41$ & $<\mathbf{0 . 0 0 1}^{\mathrm{a}}(1.54 / 4.88)$ & $<\mathbf{0 . 0 0 1}^{\mathrm{b}}(2.65 / 5.46)$ & $0.081^{\mathrm{a}}(-0.09 / 1.88)$ \\
\hline Total & $18.22 \pm 4.86$ & $13.81 \pm 2.44$ & $12.54 \pm 1.67$ & $<\mathbf{0 . 0 0 1}^{\mathrm{b}}(2.22 / 6.58)$ & $<\mathbf{0 . 0 0 1}^{\mathrm{b}}(3.86 / 7.52)$ & $\mathbf{0 . 0 0 9}^{\mathrm{b}}(0.33 / 3.24)$ \\
\hline \multicolumn{7}{|c|}{ 10-12 mm zone } \\
\hline Anterior & $33.40 \pm 14.86$ & $28.54 \pm 11.32$ & $27.15 \pm 6.47$ & $\mathbf{0 . 0 0 6}^{\mathrm{a}}(1.60 / 8.32)$ & $\mathbf{0 . 0 0 4}^{\mathrm{a}}(1.18 / 7.32)$ & $0.510^{\mathrm{a}}(-2.77 / 5.54)$ \\
\hline Central & $21.02 \pm 7.49$ & $16.51 \pm 4.75$ & $16.50 \pm 2.92$ & $\mathbf{0 . 0 1 1}^{\mathrm{a}}(0.71 / 8.31)$ & $\mathbf{0 . 0 0 3}^{\mathrm{a}}(1.61 / 6.46)$ & $0.981^{\mathrm{a}}(-1.76 / 1.80)$ \\
\hline Posterior & $17.27 \pm 5.06$ & $12.99 \pm 2.96$ & $13.21 \pm 1.78$ & $\mathbf{0 . 0 0 1}^{\mathrm{a}}(1.82 / 6.74)$ & $<\mathbf{0 . 0 0 1}^{\mathrm{a}}(2.14 / 5.96)$ & $0.681^{\mathrm{a}}(-1.33 / 0.87)$ \\
\hline Total & $23.90 \pm 8.97$ & $19.33 \pm 6.17$ & $18.95 \pm 3.53$ & $\mathbf{0 . 0 1 1}^{\mathrm{a}}(1.22 / 9.34)$ & $\mathbf{0 . 0 0 7}^{\mathrm{a}}(1.43 / 8.46)$ & $0.736^{\mathrm{a}}(-1.88 / 2.65)$ \\
\hline \multicolumn{7}{|l|}{ Total } \\
\hline Anterior & $24.05 \pm 5.75$ & $21.65 \pm 2.96$ & $18.62 \pm 1.81$ & $\mathbf{0 . 0 2 1}^{\mathrm{a}}(0.20 / 5.01)$ & $<\mathbf{0 . 0 0 1}^{\mathrm{a}}(3.39 / 7.56)$ & $<\mathbf{0 . 0 0 1}^{\mathrm{a}}(1.97 / 4.18)$ \\
\hline Central & $15.38 \pm 2.94$ & $13.43 \pm 1.66$ & $12.25 \pm 0.87$ & $\mathbf{0 . 0 0 7}^{\mathrm{a}}(0.54 / 3.34)$ & $<\mathbf{0 . 0 0 1}^{\mathrm{a}}(2.22 / 4.38)$ & $<\mathbf{0 . 0 0 1}^{\mathrm{a}}(0.75 / 1.97)$ \\
\hline Posterior & $13.10 \pm 2.30$ & $11.28 \pm 1.38$ & $10.33 \pm 0.82$ & $\mathbf{0 . 0 0 2}^{\mathrm{a}}(0.68 / 2.95)$ & $<\mathbf{0 . 0 0 1}^{\mathrm{a}}(1.84 / 3.69)$ & $\mathbf{0 . 0 0 1}^{\mathrm{a}}(0.40 / 1.48)$ \\
\hline Total & $17.56 \pm 3.61$ & $15.46 \pm 1.88$ & $13.55 \pm 1.19$ & $\mathbf{0 . 0 1 4 ^ { \mathrm { a } } ( 0 . 4 4 / 3 . 7 4 )}$ & $<\mathbf{0 . 0 0 1}^{\mathrm{a}}(2.58 / 5.23)$ & $<\mathbf{0 . 0 0 1}^{\mathrm{a}}(1.09 / 2.51)$ \\
\hline
\end{tabular}

Bold values indicate $P<0.05$.

Parenthesized italicized values indicate $95 \%$ confidence interval. ${ }^{a} t$-test with Bonferroni correction. ${ }^{\mathrm{b}}$ Mann-Whitney $U$-test with Bonferroni correction.

\section{Statistical analysis}

The study data were analyzed using the Statistical Package for Social Sciences (SPSS) software version 22.0 for Windows (SPSS Inc., Chicago, IL, USA). Descriptive statistics were presented as mean $\pm \mathrm{SD}$, frequency distribution, and percentages. The $\chi^{2}$-test was used in the analysis of the categorical variables. The normal distribution of the variables was tested by visual (histogram and probability graphs) and analytical methods (Kolmogorov-Smirnov test and Shapiro-Wilk test). When parametric analysis was possible, paired $t$-tests for paired data or Student's $t$-tests for unpaired data with Bonferroni correction were performed to compare the three groups. When parametric analysis was not possible, Wilcoxon signed-rank test for paired data and Mann-Whitney $U$-test for unpaired data were performed to compare those groups. A probability level of $P<0.05$ was considered statistically significant.

\section{Results}

The topographic records of 2751 patients with corneal ectasia were examined. A crab claw pattern on corneal topography was observed in 47 eyes of 32 patients. When the medical records of these patients were examined, PMD was detected in 11 eyes of eight patients, and inferior keratoconus was detected in 36 eyes of 24 patients. The PMD group consisted of six male and two female patients with a mean age of $50.2 \pm 11.1$ years (3166 years), and the inferior keratoconus group consisted of 12 male and 12 female patients with a mean age of $34.7 \pm 10.1$ years ( $18-56$ years). The control group consisted of 40 patients (19 males and 21 females) with a mean age of $33.1 \pm 4.6$ years (17-42 years). The mean age of the PMD group was higher than that of the other two groups $(P<0.001$ for both), but there was no statistically significant difference between the inferior keratoconus and the control groups $(P=0.458)$. The percentage of 
males in the PMD group was statistically significantly higher than in the other two groups ( $P<0.001$ for both).

Table 1 shows the results of topographic, tomographic, Belin-Ambrósio Enhanced Ectasia Display III analyses, and intergroup comparisons. The keratometric values and thinnest corneal thickness in the inferior keratoconus group were similar to those of the PMD group. The thinnest corneal point and maximum anterior and posterior elevation points were located lower in the PMD group than in the inferior keratoconus group. $Q$-values were similar in the PMD and inferior keratoconus groups, but less than those in the control group. In the PMD group, the $\mathrm{ART}_{\mathrm{avg}}$ was higher than in the inferior keratoconus group and lower than in the control group. The $\mathrm{PPI}_{\mathrm{avg}}$ was lower in the PMD group than in the inferior keratoconus group, but similar to that of the control group. In the PMD group, all $D$ indices were higher than in the control group, whereas $D$ indices, except Dt, were lower than in the inferior keratoconus group. All measured parameters in the inferior keratoconus group were significantly different from those of the control group.

Table 2 shows the corneal densitometry values of the groups and the intergroup comparison. In all groups, the corneal densitometry values were determined to be highest in the 10-12 mm zone. In addition, densitometry values were found to be highest in the anterior layer and lowest in the posterior layer in all zones, and they were significantly higher in all zones and layers of the PMD group compared with the control group. In all layers of the $0-6 \mathrm{~mm}$ zone and in the anterior layer of the $6-10 \mathrm{~mm}$ zone, the inferior keratoconus group had higher densitometry values compared with the control group. The corneal densitometry values in all layers of the 0-2 and $0-6 \mathrm{~mm}$ zones of the PMD group were similar to those of the inferior keratoconus group, but they were significantly higher in the 6-10 and 10-12 $\mathrm{mm}$ zones of the PMD group.

\section{Discussion}

Because of similar sagittal topographic features, inferior keratoconus is generally confused with PMD. ${ }^{4,5}$ However, as the prognosis and treatment are different, these two diseases must be distinguished. ${ }^{6}$ Biomicroscopic findings are very important in differential diagnosis. In

keratoconus, biomicroscopic examination usually shows a conical thinning, and the thinnest region is compatible with the most protruding region, whereas, in PMD, there is a band-like thinning and the protrusion is located just above the thinning area. Vogt's striae and the Fleischer ring are generally seen in keratoconus. Despite these different biomicroscopic features, it may be especially difficult to distinguish inferior keratoconus from early- stage PMD, and the differential diagnosis may need to be done by topographic evaluation. However, the sagittal anterior corneal curvature maps may be misleading in patients with inferior keratoconus because they do not accurately reflect the true corneal shape. Moreover, in these patients, the sagittal anterior curvature map exaggerates the presumed location of the cone and causes crab claw appearance as seen in PMD. ${ }^{5,7}$ For this reason, we need more sensitive data for differential diagnosis. Thus, the purpose of our study is to determine distinctive topographic, tomographic, and densitometric features.

In our study, 8 (11 eyes) of the 2751 patients with corneal ectasia had PMD and 24 (31 eyes) had inferior keratoconus. In a study by Lee et al ${ }^{4}$ using Orbscan II, 26 of 3993 patients with corneal ectasia had a crab claw pattern in the corneal topography, 6 (9 eyes) patients were evaluated as having PMD, and 18 (27 eyes) as having inferior keratoconus. In both studies, the probability of inferior keratoconus in patients with crab claw patterns on corneal topography was found to be three times higher than the probability of PMD. In the study of

Tummanapalli et al ${ }^{13}$ where Orbscan II was also used, 34 of 1133 patients with corneal ectasia had PMD. However, true PMD is a very rare disease. Therefore, in this study, patients with inferior keratoconus could have been diagnosed with PMD. Moreover, there are various reports about gender predilection for PMD. In our study, the male ratio in the PMD group was three times higher as in the study of Sridhar et al, ${ }^{18}$ which reported the highest number of patients in the literature.

In our study, no significant difference was found between the PMD and inferior keratoconus groups in terms of keratometry values and thinnest corneal thickness values. In the study of Lee et al, ${ }^{4}$ the mean keratometry values of PMD patients were higher than those of patients with inferior keratoconus, but the thinnest corneal thickness values were lower in PMD. The difference between this and our study may be due to the different degrees of ectasia because PMD and inferior keratoconus were not graded in either study. In another study that evaluated 49 patients with PMD by Pentacam $\mathrm{HR}$, it was found that $K_{\max }$ was lower and the thinnest corneal thickness was higher in patients with PMD than in patients with keratoconus. ${ }^{16}$ However, in that study, the borderline between PMD and keratoconus was set at the lower pupil margin for the location of corneal thinning, and, as a result of this, patients with inferior keratoconus can be misdiagnosed with PMD. In fact, it is quite difficult to find 49 patients with true PMD.

Moreover, not only patients with inferior keratoconus but also all patients with keratoconus were included in these studies.

As in previous studies, we also found that the maximum elevation points and the thinnest corneal 
region were lower in PMD than in keratoconus. $4,13,14,16$ However, the most important difference in our study from these other studies was that our study examined patients with inferior keratoconus that was topographically similar to PMD, not patients with classical keratoconus, because the differential diagnosis of PMD and classical keratoconus is not as difficult to determine as that of PMD and inferior keratoconus. However, it should be remembered that corneal topography systems usually evaluate the $9 \mathrm{~mm}$ central part of the cornea, and, in $45 \%$ of the patients with PMD, the thinnest region of the cornea was found to be outside of the $9 \mathrm{~mm} .{ }^{14}$ Therefore, the thinnest corneal thickness values and their coordinates presented in topography systems may not reflect actual values, and the full pachymetric map (in the $12 \mathrm{~mm}$ corneal area) should be evaluated as in our study. In addition, as the peripheral region of the cornea is thicker than the central region, the thinning of the peripheral cornea may not fall below the central corneal thickness in the early stage of PMD. For this reason, the placement of the thinnest points near the center of the cornea does not exclude PMD. In our study, the coordinates of the thinnest corneal thickness and the maximum elevation points in the $y$ axis were evaluated, but not the coordinates in the $x$ axis. Because of the conelike protrusion in keratoconus, the thinnest point and the maximum elevation points are localized near the top of the cone. As PMD has a band-like protrusion, points with similar thickness and elevation values can be localized far from each other on the $x$ axis. Assessment of Scheimpflug images, especially including inferior quadrants and with a full-thickness pachymetric map, may also help distinguish between PMD and inferior keratoconus. In advanced PMD, the Scheimpflug image may show thinning of the peripheral cornea and protrusion over this thinning area. ${ }^{7}$

In the study of Tummanapalli et al, ${ }^{13}$ the $Q$-values were found to be 0.14 in patients with PMD and -0.51 in patients with classical keratoconus. In the study of Koçluk et $a,^{14}$ the $Q$-values were 0.09 in patients with PMD and -0.54 in patients with inferior keratoconus. In these two studies, it was determined that the $Q$-value can be used to distinguish between PMD and keratoconus. However, in our study, the $Q$-value was found to be -0.05 in patients with PMD and -0.04 in patients with inferior

keratoconus, and there was no difference between the two groups. The difference in the results of our study from those of other studies may be related to the differences in patient selection and measurement methods. It should also be noted that the SD of the $Q$-values determined in our study was high. The range of the distribution of the $Q$-values was considerably wider in the study of Koçluk et al, where the study groups were closer to those of our study. For this reason, we think that the $Q$-values should not be used in differential diagnosis of PMD and inferior keratoconus. Another issue to be considered when interpreting the $Q$-values and the corneal thickness and elevation values determined in these studies is that the measurement methods, such as Scheimpflug camera and slit-scanning that were used in these studies, may have affected the values.

Belin-Ambrósio Enhanced Ectasia Display analysis provides a more comprehensive display for ectasia screening, especially in refractive corneal surgery candidates. BFS and enhanced BFS are used in this analysis. Enhanced BFS is created by subtracting the $4 \mathrm{~mm}$ circular zone (exclusion zone) surrounding the thinnest corneal point. The goal of using enhanced BFS is to increase the sensitivity of the analysis by excluding the ectatic region. In this analysis, the cornea is evaluated first with BFS and then with enhanced BFS, and the difference between the two evaluations is presented as deviation indices (Df, Db, Dp, Dt, Da, and final D) by regression analysis. The normal limits of deviation indices are calculated according to the database of keratoconus patients. ${ }^{19}$ To the best of our knowledge, there is no study evaluating the D indices of patients with PMD. In our study, the D indices of patients with PMD were evaluated and found to be higher than those of the control group. All the indices, except Dt, were found to be lower in the PMD group than in the inferior keratoconus group. The reason for this could be that the exclusion zone in patients with PMD may not be able to cover the ectasia area as much for patients with keratoconus because the ectatic zone is cone-shaped in keratoconus and it mostly remains in the circular exclusion zone. In PMD, the ectatic region is wider and band-like in shape; therefore, the part outside of the exclusion zone is greater, and the sensitivity of D indices in patients with PMD may be lower. In addition, when interpreting our results, it should be noted that the BAD analysis was developed for ectasia scanning, that it does not involve the analysis of corneal area outside $9 \mathrm{~mm}$, and that the database used for analysis was obtained from patients with keratoconus. Therefore, BAD analysis may not be suitable for patients with PMD. As is known, corneal ectasia may develop after refractive surgery in patients without any risk factors, and some of these patients may develop PMD in later years. ${ }^{20}$ Because refractive surgery candidates are usually young and PMD is most often seen in the later years of life, it may therefore be helpful to use the databases of especially early-stage PMD patients to determine the normal limits of the $D$ indices.

Corneal densitometry values in the central region increase in keratoconus because the epithelial layer structure and stroma are disrupted and the light backscatter increases in parallel. $8,11,21,22$ In our study, it was detected that corneal densitometry values increased 
in the central $6 \mathrm{~mm}$ zone in patients with inferior keratoconus, whereas there was no significant difference in the area outside of the $6 \mathrm{~mm}$ zone compared with the control group. This finding may show that, although steepening is located at the inferior cornea, structural deterioration in the central cornea is more prominent in inferior keratoconus. Although the densitometric properties of the cornea with keratoconus have been studied previously, the densitometric properties of the cornea with PMD have not been studied. In our study, it was found that the PMD group had significantly increased densitometry values in all zones and layers compared with the control group. This finding may indicate that PMD affects not only the inferior cornea but the entire cornea. Tummanapalli et $a^{13}$ also found that the thickness of the cornea in PMD was thinner than normal, not only on the inferior quadrant but also on all quadrants of the cornea. When the PMD group was compared with the inferior keratoconus group, the densitometry values in the 6-10 and 10-12 mm zones were higher in the PMD group. The difference was more significant in the 6$10 \mathrm{~mm}$ zone. This difference may be related to lower localization of corneal ectasia in the PMD and the effect of PMD on the wider corneal area. Thus, it should be examined with studies involving a large number of patients as to whether the densitometric difference between the two groups can be used in differential diagnosis. However, this difference must be interpreted with caution. There is a significant age difference between the two groups because PMD is seen at a later age, and, as age increases, corneal densitometry values increase. ${ }^{23}$

We have to emphasize one specific point about our study. We classified the patients according to their clinical findings as in previous studies. ${ }^{4,13}$ This classification may be problematic in the differentiation of early-stage PMD from inferior keratoconus. It would be more accurate to use the full-thickness map in these patients. However, we did not classify the patients according to the corneal thickness as extrapolated data are available for some patients in the full-thickness map. This negative condition is due to the retrospective design of our study, and it demonstrates that we could not perform corneal thickness measurements from a $12 \mathrm{~mm}$ area with high reliability in some patients. However, we think it would be more appropriate to classify patients according to the corneal thickness map with a $12 \mathrm{~mm}$ area with minimal extrapolated data in future prospective studies.

The most important limitation of our study was its retrospective design. We did not measure corneal densitometry at the same time of the day because of the retrospective nature of the study, and this influenced our results because corneal hydration shows a diurnal variation and corneal transparency can be affected by this variation. ${ }^{24,25}$ Another drawback of the study was the small sample size, which may affect the validity of our results. These findings and their clinical significance must be further investigated by studies with larger sample sizes. One of the limitations of our study is that we have not considered the kappa angle. This is pertinent because, as is known, anterior curvature maps may show inferior asymmetric steepening similar to keratoconus in normal subjects, and they can have a significant difference between the measurement axis and the visual axis. ${ }^{26}$ Similarly, peripheral steepness can be seen in the sagittal curvature map of the keratoconus patients with a high kappa angle, although the cone is in the paracentral region.

In conclusion, the distinction between PMD and inferior keratoconus must be made and the appearance of a crab claw pattern on the topography is not sufficient for differential diagnosis. Furthermore, it is important to realize that true PMD is a very rare disease, and patients with crab claw patterns on the sagittal map are much more likely to have inferior keratoconus than those with PMD. The presence of an arcuate-shaped peripheral thinning and protrusion on the thin area should be considered on the biomicroscopic examination of these patients. The full $12 \mathrm{~mm}$ corneal thickness map and Scheimpflug images must be examined. Biomicroscopic and topographic discrimination may be difficult in early-stage patients. In these patients, the tomographic (thinnest corneal point and maximum elevation points, $\mathrm{D}$ indices) and densitometric (6-12 mm zone) evaluation may be helpful in differential diagnosis.

\section{Summary}

What was known before

- Because of the similar topographic features, inferior keratoconus is generally confused with PMD.

- Anterior corneal surface analysis without additional information is not sufficient in the differential diagnosis of inferior keratoconus and PMD.

What this study adds

- PMD is a very rare disease; the patients with crab claw patterns on the sagittal map are much more likely to have inferior keratoconus than those with PMD.

- Deviation indices from Belin-Ambrósio Enhanced Ectasia Display III analysis are lower in the patients with PMD than those in the inferior keratoconus.

- Corneal densitometry values in the 6-10 and 10-12 mm zones in the PMD are higher than those in the inferior keratoconus.

\section{Conflict of interest}

The authors declare no conflicts of interest. 


\section{Acknowledgements}

This research received no specific grant from any funding agency in the public, commercial, or not-for-profit sectors. We would like to thank Zafer Gökhan Kalıpçığlu for the measurements of all our patients and also extend our gratitude to Doctor Onder Aydemir from the Department of Public Health, Gazi University Faculty of Medicine for his assistance in the statistical analysis.

\section{References}

1 Krachmer JH. Pellucid marginal corneal degeneration. Arch Ophthalmol 1978; 96: 1217-1221.

2 Maguire LJ, Klyce SD, McDonald MB, Kaufman HE. Corneal topography of pellucid marginal degeneration. Ophthalmology 1987; 94: 519-524.

3 Rabinowitz YS. Keratoconus. Surv Ophthalmol 1998; 42(4): 297-319.

4 Lee BW, Jurkunas UV, Dagher MH, Poothullil AM, Tobaigy FM, Azar DT. Ectatic disorders associated with a clawshaped pattern on corneal topography. Am J Ophthalmol 2007; 144: 154-156.

5 Belin MW, Asota IM, Ambrosio R Jr, Khachikian SS. What's in a name: keratoconus, pellucid marginal degeneration, and related thinning disorders. Am J Ophthalmol 2011; 152: 157-162.

6 Gruenauer-Kloevekron C, Fischer U, Kloevekorn-Norgall K, Duncker GIW. Pellucid marginal corneal degeneration: evaluation of the corneal surface and contact lens fitting. $\mathrm{Br} J$ Ophthalmol 2006; 90: 318-323.

7 Walker RN, Khachikian SS, Belin MW. Scheimpflug photographic diagnosis of pellucid marginal degeneration. Cornea 2008; 27: 963-966.

8 Lopes B, Ramos I, Ambrósio R Jr. Corneal densitometry in keratoconus. Cornea 2014; 33: 1282-1286.

9 Alnawaiseh M, Zumhagen L, Wirths G, Eveslage M, Eter N, Rosentreter A. Corneal densitometry, central cornea thickness and corneal central-to-peripheral thickness ratio in patients with Fuchs endothelial dystrophy. Cornea 2016; 35: 358-362.

10 Jester JV, Moller-Pedersen T, Huang J, Sax CM, Kays WT, Cavangh HD et al. The cellular basis of corneal transparency: evidence for 'corneal crystallins'. J Cell Sci 1999; 112: 613-622.

11 Mathew JH, Goosey JD, Söderberg PG, Bergmanson JPG. Lameller changes in the keratoconic cornea. Acta Ophthalmol 2015; 93: 767-773.

12 Smolek MK, Beekhuis WH. Collagen fibril orientation in the human corneal stroma and its implications in keratoconus. Invest Ophthalmol Vis Sci 1997; 38: 1289-1290.
13 Tummanapalli SS, Maseedupally V, Mandathara P, Rathi VM, Sangwan VS. Evaluation of corneal thickness indices in pellucid marginal degeneration and keratoconus. J Cataract Refract Surg 2013; 39: 56-65.

14 Koçluk Y, Akkaya-Yalniz Z, Burcu A, Örnek F. Comparison of Scheimpflug imaging analysis of pellucid marginal corneal degeneration and keratoconus. Ophthalmic Res 2015; 53: 21-27.

15 Oie Y, Maeda N, Kosaki R, Suzaki A, Hirohara Y, Mihashi T et al. Characteristics of ocular higher-order aberrations in patients with pellucid marginal corneal degeneration. J Cataract Refract Surg 2008; 34: 1928-1934.

16 Fuchihata M, Maeda N, Toda R, Koh S, Fujikado T, Nishida $\mathrm{K}$. Characteristics of corneal topographic and pachymetric patterns in patients with pellucid marginal degeneration. Jpn J Ophthalmol 2014; 58: 131-138.

17 Krachmer JH, Feder RS, Belin MW. Keratoconus and related non inflammatory corneal thinning disorders. Surv Ophthalmol 1984; 28: 293-322.

18 Sridhar MS, Mahesh S, Bansal AK, Nutheti R, Rao GN. Pellucid corneal degeneration. Ophthalmology 2004; 111: 1102-1107.

19 Villavicencio OF, Gilani F, Henriquez MA, Izquierdo Jr L, Ambrósio Jr R, Belin MW. Independent population validation of the Belin/Ambrósio Enhanced Ectasia Display: implications for keratoconus studies and screening. Int $\mathrm{J}$ Kerat Ect Cor Dis 2014; 3: 1-8.

20 Fogla R, Rao K, Padmanabhan P. Keratectasia in 2 cases with pellucid marginal corneal degeneration after laser in situ keratomileusis. J Cataract Refract Surg 2003; 29: 788-791.

21 Smolek MK, Beekhuis WH. Collagen fibril orientation in the human corneal stroma and its implications in keratoconus. Invest Ophthalmol Vis Sci 1997; 38: 1289-1290.

22 Anayol MA, Sekeroglu MA, Ceran BB, Mehmethan Dogan, Gunaydin S, Yilmazbas P. Quantitative assessment of corneal clarity in keratoconus: a case control study of corneal densitometry. Eur J Ophthalmol 2016; 26: 18-23.

23 Dhubhghaill SN, Rozema JJ, Jongenelen S, Ruiz Hidalgo I, Zakaria N, Tassignon MJ. Normative values for corneal densitometry analysis by Scheimpflug optical assessment. Invest Ophthalmol Vis Sci 2014; 55: 162-168.

24 Niimi J, Tan B, Chang J, Zhou Y, Ghanekar A, Wong M et al. Diurnal pattern of tear osmolarity and its relationship to corneal thickness and deswelling. Cornea 2013; 32: 1305-1310.

25 Read SA, Collins MJ. Diurnal variation of corneal shape and thickness. Optom Vis Sci 2009; 86: 170-180.

26 Belin MW, Khachikian SS. An introduction to understanding elevation-based topography: how elevation data are displayed-a review. Clin Experiment Ophthalmol 2009; 37: $14-29$. 